\title{
KAJIAN ESTETIKA TIMUR PADA RUMAH ADAT SOPO GODANG MANDAILING
}

\author{
Anni Kholilah ${ }^{1 *}$, Niko Andeska ${ }^{2 *}$, Muhammad Ghifari ${ }^{3 *}$ \\ Jurusan Seni Rupa dan Desain \\ Institut Seni Budaya Indonesia (ISBI) Aceh \\ Jl. Transmigrasi, Gampong Bukit Meusara, Kec. Kota Jantho, Kab. Aceh Besar, 23911. \\ Aceh. Indonesia \\ Email:annikholilah@isbiaceh.ac.id
}

\begin{abstract}
Abstrak
Sopo Godang merupakan balai sidang adat di daerah Mandailing Natal. Bangunannya menggunakan tiang-tiang besar yang berjumlah ganjil termasuk anak tangganya. Sopo Godang adalah sebuah bangunan yang terbentuk empat persegi panjang, terbuka dan tidak memiliki dinding. Ukurannya juga lebih kecil dari bagas godang. Sopo Godang dianggap sebagai tempat yang sacral karena adat dan hukum adat dijiwai oleh sopo godang. Dari gedung inilah turun keputusan-keputusan yang mengatur tata tertib seperti patik, uhum, ugari, dan hapantunon. Sopo Godang ini disebut juga sopo siorancang magodang karena gedung ini adalah tempat orang memperoleh perlindungan yang aman. Sopo Godang sengaja dibuat tidak berdinding agar rakyat secara langsung dapat melihat dan mendengar segala hal yang dibicarakan oleh raja dan namora natoras sebagai pemimpin mereka. Tidak ada yang tertutup tapi semua berlangsung secara transparan. Sopo godang ini sangatlah unik, sirih bersusun yang di sodorkan, merupakan tutur kata dan sopan santun yang tidak ternilai harganya. Dengan sirih orang akan mudah memberi sesuatu, mudah memaafkan, mudah berbuat, mudah menolong dan sebagainya. Perlengkapan sirih yang terdiri dari sirih, gambir, kapur sirih, pinang, dan tembakau mempunyai arti tersendiri di dalam upacara. Penelitian ini akan menggunakan metode deskriptif kualitatif untuk mendapatkan suatu gambaran yang menyeluruh dan mendalam mengenai pokok bahasan. Dalam hal ini, menampilkan analisis terhadap Estetika yang terdapat pada Rumah Adat Sopo Godang Mandailing khususnya dilihat dari estetika timur.
\end{abstract}

Kata Kunci: estetika timur, rumah sopo godang.

\begin{abstract}
Sopo Godang is a custom court for people around there, in Bahasa we called it "Balai Sidang". Sopo Godang is located in Mandailing Natal. The architecture is built from big poles in odd quantity, also its stairs. Sopo Gadang is a rectangle building, one of open space building with no walls around it. The size is smaller than bagas godang. Sopo godang considered to be a holy place because of custom and customary law which imbued by Sopo godang. In this building, the decision which set the order of patik, uhum, ugari, dan hapantunon. Sopo Godang is also called sopo siorancang magodang because this building is a place where people look for safety place. Sopo Godang is deliberately built without wall in order to give the opportunity for society seiing and hearing directly every words of their king and namora natoras as their leader. Thus, there were transparancy between them. Sopo godang is very unique, such as sirih bersusun, it is simbolize a good things in speaking and polite manner which is priceless. People believed that sirih brings a good attitude, such as generous, forgiving, being kind, helping each other easily, and the others. The equipment of sirih : sirih, gambir, kapur sirih, pinang, and tobacco have its own meaning in the ceremony. This research used descriptive qualitative approach to obtain a comprehensive and analitical description about this topic. This research used East Aesthetic theory for analizing the findings Malangan.
\end{abstract}

Keywords: east aesthetic, rumah sopo godang.

\section{PENDAHULUAN}

Sopo Godang adalah sebuah bangunan yang terbentuk empat persegi panjang, terbuka dan tidak memiliki dinding. Ukurannya juga lebih kecil dari bagas godang. Apabila huta atau kampung telah diresmikan sesuai dengan ketentuan adat, maka huta itu disebut bona bulu. ciri-ciri huta yang menjadi bona bulu adalah jika disekeliling kampung itu telah ditanam dengan bambu, beringin, yang disamping sebagai pembatas juga merupakan benteng untuk menangkal serangan musuh baik yang nyata maupun yang tidak nyata. Huta yang sudah merupakan bona bulu mempunyai bagas godang sebagai tempat kediaman 


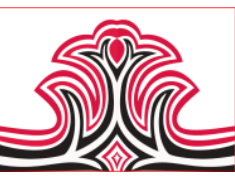

raja dan sopo godang sebagai tempat (balai) pertemuan.

Sopo Godang merupakan tempat bermusyawarah dan bermufakat dalam menyelesaikan permasalahan yang terjadi di masyarakat, disamping itu Sopo Godang juga merupakan simbol daerah Kabupaten Mandailing Natal. Bangunannya mempergunakan tiang-tiang besar yang berjumlah ganjil sebagaimana juga jumlah anak tangganya.

Sopo Godang dianggap sebagai tempat yang sakral karena adat dan hukum adat dijiwai oleh sopo godang. Dari gedung inilah turun keputusan-keputusan yang mengatur tata tertib seperti patik, uhum, ugari, dan hapantunon. Sopo Godang ini disebut juga sopo dirancang magodang karena gedung ini adalah tempat orang memperoleh perlindungan yang aman. Sopo Godang sengaja dibuat tidak berdinding agar rakyat secara langsung dapat melihat dan mendengar segala hal yang dibicarakan oleh raja dan namora natoras sebagai pemimpin mereka. Tidak ada yang tertutup tapi semua berlangsung secara transparan.

Sopo godang ini sangatlah unik dan terdapat berbagai macam bentuk ornamen hiasan tradisional dan ditemukan pada bagian tutup ari dari Sopo Godang (Balai Sidang Adat). Ornamen sopo godang ini dalam bahasa mandailing disebut bolang yang juga berfungsi sebagai simbol atau lambang yang memiliki maknamakna yang sangat mendalam bagi masyarakat Mandailing. Di dalamnya terkandung nilai-nilai, gagasan-gagasan, konsep-konsep, norma-norma, kaidah-kaidah, hukum dan ketentuan adat-istiadat yang menjadi landasan dan pegangan dalam mengharungi bahtera kehidupan.

Bolang atau ornament tradisional Mandailing yang digunakan sebagai Tutup Ari itu terbuat dari tiga jenis material:

Pertama Tumbuh-tumbuhan, seperti batang bambu yang melambangkan huta atau bona bulu burangir atau aropik melambangkan Raja dan Namora Natoras sebagai tempat meminta pertolongan, pusuk nirobung yang disebut bindu melambangkan adat Dalian $\mathrm{Na}$ Tolu atau adat Markoum-Sisolkot

Kedua Hewan atau binatang, seperti hala dan lipan melambangkan "bisa" yang mempunyai kekuatan hukum, ulok melambangkan kebesaran dan kemuliaan; parapoti melambangkan kegiatan mencari nafkah untuk menghidupi keluarga, tanduk ni orbo melambangkan bangsawanan
Gorga Jurnal Seni Rupa

Volume 08 Nomor 02 Juli-Desember 2019 p-ISSN: 2301-5942 | e-ISSN: 2580-2380

Ketiga Peralatan hidup sehari-hari, seperti timbangan dan podang melambangkan keadilan; takar melambangkan pertolongan bagi yang membutuhkan; loting melambangkan usaha-usaha dalam mencari nafkah, dan lain sebagainya.

Setiap kelompok masyarakat mempunyai ketentuan yang harus di ikuti dan dipatuhi oleh warganya untuk kesejahteraan masyarakat itu sendiri. Dan ketentuan itu harus di dasari oleh falsafah hidup yang merupakan nilai luhurnya. Nilai-nilai luhur itu sudah terpatri dalam jiwa yaitu holong dan domu. Holong dan domu ini merupakan perasaan satu kesatuan yang harus tertanam di dirinya. Bila sopo godang berdiri, raja wajib memotong kerbau untuk meresmikannya. Selama sopo godang berdiri kokoh semua keputusankeputusan dipatuhi rakyat, masyarakat tentram dan sejahtera. Jika sopo godang roboh maupun fungsinya, sejak itulah masyarakat mandailing mulai tidak teratur aturan-aturan bermasyarakat.

\section{KAJIAN TEORI}

\section{State of The Art}

Pada penelitian yang akan dilaksanakan terlebih dahulu dilakukan tinjauan pustaka tentang Rumah Adat Sopo Godang Mandailing dengan kajian estetika timur. Hal ini dilakukan guna memperkaya pembahasan pada penelitian yang akan dilakukan. Tinjauan pustaka pada penelitian ini terdiri atas buku dan jurnal penelitian, antara lain:

Adat Budaya Mandailing dalam Tantangan Zaman, oleh H. Pandapotan Nasution,SH. 2005. Pada buku ini membahas tentang budaya masyarakat mandailing yang dimana di dalamnya menceritakan tentang perkembangan budanya mulai dari wilayahnya sampai kepengaruh modernisasi. Disamping huta sebagai wadah tempat tinggal kelompok masyarakat adat mandailing, dikenal kelompok-kelompok masyarakat lainnya yaitu: banjar, lumban, pagaran, janjian.

Adat Hangoluan Mandailing, Tapanuli Selatan oleh Drs.H Syahmerdan Lubis Gelar Baginda Raja Muda. Dimana dalam buku tentang adat patujolona, perlengkapan untuk adat pernikahan sampai penyelesaian adat kematian dan pemikiran untuk pelestarian adat kedepannya. Di dalamnya terkandung nilai-nilai, gagasan-gagasan, konsep-konsep, normanorma, kaidah-kaidah, hukum dan ketentuan adat-istiadat yang menjadi landasan dan pegangan dalam mengharungi bahtera kehidupan. Bolang atau ornament tradisional Mandailing yang digunakan sebagai Tutup Ari perlambang itu terbuat dari tiga 
jenis material. Pembuatan ornamen pada Sopo Godang dan Bagas Godang ini dilakukan dengan cara menganyam atau menjalin dan ada pula yang diukir. Bahan yang dipakai sebagai bahan anyaman adalah lembaran-lembaran bambu yang telah diarit dengan bentuk-bentuk terentu dan kemudian dipasang pada bagian tutup ari. Ornamen-ornamen itu sebagian besar diberi warna merah, na hitam dan na putih yang erat kaitannya dengan kosmologi Mandailing. Dalam hal ini, merah melambangkan kekuatan, keberanian dan kepahlawanan; Putih melambangkan kesucian, kejujuran dan kebaikan; Hitam melambangkan kegaiban (alam gaib) dalam sistem kepercayaan animisme yang disebut Sipelebegu.

Bentuk Dan Fungsi Rumah Adat Raja Pamusuk Mandailing, oleh Anni Kholilah. Rosta Minawati dan Zulhelm Raja Pamusuk adalah raja yang berada di bawah Raja Ihutan, yang memimpin satu huta. Dalam masyarakat Mandailing sejarah lahirnya raja tidak dapat dipisahkan dengan sejarah terbentuknya huta. Raja telah mengubah suatu huta menjadi suatu tempat yang lebih cocok dan lebih enak ditinggali. Pengertian raja di Mandailing bukanlah raja yang absolute, tapi raja sebagai sesepuh yang di dahulukan selangkah, di tinggikan seranting. Itulah sebabnya pada waktu terjadi repolusi 45 raja- raja di Mandailing tidak di musuhi rakyat seperti di daerah lain, malah mereka menyatu dengan rakyat untuk bersama - sama untuk membebaskan Indonesia dari penjajahan Belanda. Hal ini menunjukkan adanya batasan yang jelas antara tata pemerintahan dengan adat - istiadat, meskipun terjadi perubahan dalam kelembagaan pemerintahan, namun adat dan tradisi akan tetap lestari sebagai khazanah budaya Mandailing (Nasution, Pandapotan, H, SH, 2005: 31). Dari uraian diatas dapat disimpulkan, bahwa penyelenggaraan kekuasaan pemerintahan oleh raja-raja dalam kesatuan masyarakat adat mandailing, ternyata adalah menerapkan system pemerintahan dan ketatanegaraan seperti saat ini. Struktur pemerintahan raja-raja mandailing telah memilik ialat-alat kelengkapan Negara, seperti majelis rakyat(kerapatan adat/ kerapatan sopo godang), legislatif (namora natoras), kabinet (pembantu-pembantu raja dalam pelaksanaan pemerintahan) dan adanya sumber penghasilan dengan system pemungutanpemungutan dari hasil-hasil di daerah itu. Rumah adat Mandailing merupakan arsitektur yang khas. Bagas godang berfungsi sebagai tempat tinggal raja panusunan maupun raja pamusuk sebagai pemimpin huta. Biasanya bagas godang raja panusunan lebih besar dari raja pamusuk. Secara adat bagas godang melambangkan bona bulu yang berarti bahwa huta tersebut telah memiliki satu perangkat adat yang lengkap seperti dalihan natolu, namora natoras, datu, sibaso, ulu balang, panggora, dan raja pamusuk sebagai raja adat.

1. Selain tempat penyelenggaraan upacara adat, bagas godang juga berfungsi sebagai tempat perlindungan bagi anggota masyarakat yang dijamin keamanannya oleh raja. Penutup sisi atap diatas tangga depan yang berbentuk segitiga disebut juga alo angin (tamparan angin) atau tutup ari melambangkan bindu matogu sebagai perlambang dalihan na tolu.

Bentuk Dan Fungsi Sopo Godang Tapanuli Selatan Mandailing Natal. Oleh Anni Kholilah. Pada penelitian ini membahas bentuk dan fungsi Sopo Godang Mandailing Natal dalam hal kehidupan masyarakat Mandailing meliputi rumah adat, dan kekeluargaan. Pembahasan lebih bersifat deskriptif yang diharapkan paling tidak dapat memberi gambaran tentang keberadaan Sopo Godang Mandailing Natal. Sopo Godang dapat diartikan sebagai rumah besar, berasal dari bahasa Batak yang biasanya digunakan sebagai tempat pesta atau acara besar mulai dari pesta perkawinan, Ulang Tahun atau pertemuan-pertemuan besar yang melibatkan banyak orang. Unik Sopo Godang adalah milik umum, dan dipakai oleh umum. Tidak seperti terjamahan bebasnya "Rumah Besar" Sopo Godang adalah seni dari Rumah biasa yang ditempati oleh manusia. Sopo Godang biasanya terdiri dari ruang besar yang bisa menampung banyak orang. Rumah adat juga sebagai tempat untuk bersilaturrahmi dengan para pemerintahan dan kerabat setempat. Dalam rumah adat ini selalu terpajang seperangkat alat kesenian khas Mandailing yang disebut dengan gordang sembilan. Rumah adat adalah salah satu tempat adat dan budaya yang sangat khas. Dilihat dari fungsi, rumah adat Mandailing mencerminkan keagungan Huta sebagai sebuah masyarakat yang mampu berdiri sendiri, salah stunya yaitu dengan membentuk dan menjalankan pemerintahannya sendiri dan serta mempertahankan budayanya sendiri.

\section{METODE PENELITIAN}

\section{Rancangan Penelitian}

Dalam penelitian ini menggunakan metode deskriptif kualitatif untuk mendapatkan suatu gambaran yang menyeluruh dan mendalam mengenai pokok bahasan. Dalam hal ini, menampilkan analisis terhadap Estetika yang terdapat pada Rumah Adat Sopo Godang Mandailing khususnya dilihat dari estetika timur. 


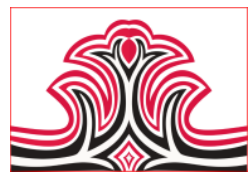

2.Lokasi

Lokasi dalam penelitian ini adalah di Desa Huta Godang, Kecamatan Ulu Pungkut, Kabupaten Mandailing Natal, Provinsi Sumatera Utara.

\section{Teknik Pengumpulan Data}

Pengumpulan data dilakukan untuk mendapatkan dan memperoleh informasi terkait objek yang akan diteliti untuk mencapai tujuan penelitian. Adapun teknik pengumpulan data yang digunakan dalam penelitian ini adalah:

\section{1).Observasi}

Observasi adalah metode pengumpulan data melalui pengamatan langsung atau peninjauan secara cermat dan langsung di lapangan atau lokasi penelitian. Dalam hal ini observasi dilakukan dengan mengunjungi lokasi-lokasi penelitian seperti di Desa Huta Godang sebagai tempat yang masih banyak terdapat rumah adat sopo godang.

\section{2).Wawancara}

Metode wawancara dilakukan untuk mendapatkan data secara lisan tentang Rumah Adat Sopo Godang di Desa Huta Godang. Adapun tokoh masyarakat yang akan diwawancarai adalah pemuka adat yang mengetahui tentang seluk beluk rumah adat sopo godang.

\section{3).Dokumentasi}

Metode dokumentasi dilakukan untuk mengumpulkan data di lapangan berupa bukti fisik bentuk rumah adat sopo godang. Adapun dokumen-dokumen yang akan dikumpulkan yaitu berupa video ataupun foto-foto rumah adat sopo godang.

\section{4).Studi Pustaka}

Studi pustaka dilakukan untuk menjadi bahan acuan ataupun perbandingan terhadap estetika rumah adat sopo godang. Studi pustaka diperlukan sebagai referensi untuk memperoleh informasi dari penelitian terdahulu mengenai objek material ataupun objek formal rumah adat sopo godang.

\section{Teknik Analisis Data}

Data yang diperoleh dari hasil penelitian selanjutnya akan dianalisis secara kualitatif. Penelitian ini adalah deskriptif yaitu memberikan dan menggambarkan fakta suatu keadaan mengenai objek penelitian tanpa ada rekayasa pada data-data yang telah diperoleh.

\section{1).Reduksi}

Pada tahap reduksi ini, dilakukan pemusatan dan pemilihan data-data yang muncul dilapangan. Proses
Gorga Jurnal Seni Rupa

Volume 08 Nomor 02 Juli-Desember 2019

p-ISSN: 2301-5942 | e-ISSN: 2580-2380

reduksi dilakukan selama penelitian berlangsung hingga proses penyusunan laporan.

\section{2).Penyajian Data}

Penyajian data merupakan tahap kedua dalam teknik analis data. Penyajian data dilakukan saat data-data dan informasi yang didapatkan di lapangan telah dikumpulkan. Kemudian, data-data tersebut disusun dan dilakukan analisis sehingga memungkinkan adanya penarikan kesimpulan yang berhubungan dengan latar belakang penelitian.

\section{3).Verifikasi dan Kesimpulan}

Tahap terakhir dari teknik analisis data adalah verifikasi dan kesimpulan.

\section{HASIL DAN PEMBAHASAN}

\section{Hasil}

Hasil penelitian yang dilaksakan pada bangunan Rumah Adat Sopo Godang Mandailing dalam kajian estetika timur, dapat disimpulkan bahwa sopo godang memiliki tiga bagian yang akan dibahas yaitu tentang roh dan kepercayaan, bentuk, komposisi, dan warna yang kan menyangkut dengan kajian estetika timur pada sopo godang.

Sopo godang adalah rumah adat orang Mandailing Natal, tempat musyawarah, tempat berkesenian dan lain-lain. Sopo Godang merupakan tempat memusyawarahkan peraturan adat. Selain itu, tempat ini juga dijadikan untuk pertunjukan kesenian, tempat belajar adat dan kerajinan, bahkan juga tempat musyafir bermalam. Berbagai patik, uhum, ugari dan hapantunan lahir dari tempat ini. Juga disiapkan untuk menerima tamu-tamu terhormat. Dirancang berkolong dan tidak berdinding agar penduduk dapat mengikuti berbagai kegiatan di dalamnya. Karenanya Sopo Godang juga disebut Sopo Sio Rangcang Magodang, inganan ni partahian paradatan, parosu-rosuan ni hula dohot dongan. Artinya, Balai Sidang Agung, tempat bermusyawarah melakukan sidang adat, menjalin keakraban para tokoh terhormat dan para kerabat. Pada gambar dibawah ini terlihat bagian dalam rumah adat Sopo Godang serta terdapat gondang sembilan. 

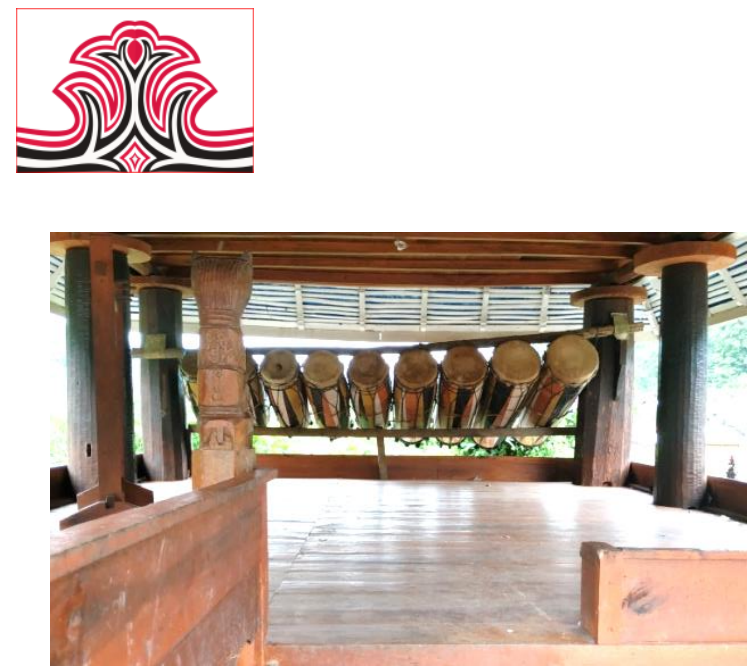

Gambar 1. Gondang Sembilan

(Sumber: Muhammad Ghifari, 2019)

Bagian dari ornamen yang berbentuk segi tiga yang disebut dengan tutup ari, bindu atau pusuk robung, melambangkan sistem sosial Dalian Natolu yang dianut oleh masyarakat setempat. Bangunan sopo godang (balai sidang adat) tidak berdinding. Keadaannya yang demikian itu melambangkan pemerintahan yang harus dijalankan secara demokratis. Garis-garis geometris (garis lurus) kecuali yang menggambarkan benda-benda alam seperti matahari, bulan dan bintang serta bunga. Fungsi utama dari ornamen tersebut bukan sekadar sebagai hiasan, tetapi berfungsi simbolik untuk menunjukkan banyak hal yang berkaitan dengan nilai budaya dan pandangan hidup masyarakat Mandailing. Bagianbagian dari bangunan bagas godang diberi nama juga mengandung makna simbolik.

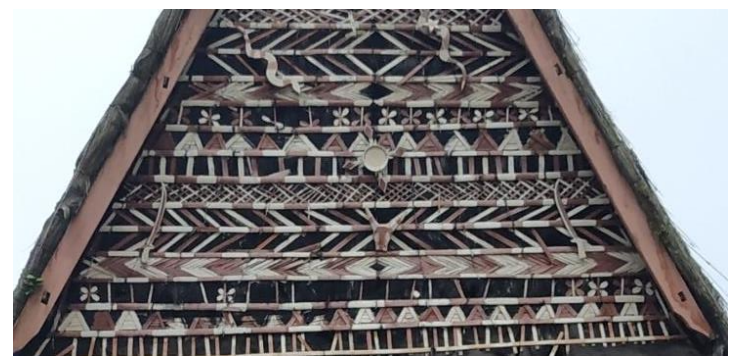

Gambar 2. Tutup Ari Rumah Adat Sopo Godang (Sumber: Muhammad Ghifari, 2019)

\section{Pembahasan}

Sopo godang bukanlah sopo yang biasa, melainkan sopo yang mempunyai nilai luhur dari nenek moyang masyarakat itu sendiri. Kalau dikaji dalam estetika timur disini kita akan melihat sesuatu kepercayaan bagi masyarakat, dalam suatu pembangunan bersipat kepercayaan terhadap alam gaip maupun roh-roh. Dalam pembangunan sopo godang seperti bahan yang digunakan termasuk kayu, kayu yang digunakan tidak sembarangan kayu, melainkan harus betul-betul kayu yang kokoh dan kuat. Kayu yang digunakan adalah kayu yang berada ditengah-tengah hutan, dalam pencarian kayu ada sebuah unsur kepercayaan
Gorga Jurnal Seni Rupa

Volume 08 Nomor 02 Juli-Desember 2019 p-ISSN: 2301-5942 | e-ISSN: 2580-2380

masyarakat yaitu memanggil si baso (mahluk gaib). Pemanggilan sibaso dilakukan oleh orang yang dipercaya masyarakat mempunyai ilmu terhadap halhal yang kasat mata. Mendirikan sebuah bangunan tradisional harus melewati suatu ketentuan-ketentuan yang sudah menjadi kebiasaan atau tradisi yang di atur masyarakat, seperti pemilihan kayu untuk pembangunan rumah adat akan dipilih oleh si baso (mahluk gaib).

Dalam pendirian bangunan sopo godang akan di musyawarahkan dan ditentukan oleh ketua adat dan pimpinan (raja) daerah. Musyawarah tersebut akan ditetapkan semua persyaratan yaitu cara mendirikan bangunan, penetuan hari, bulan dan jam, pemilihan bahan bangunan berupa tiang-tiang, dindin, atap, pertapakan tanah, arah bangunan, pola hiasan atau ornamen yang melambangkan adat istiada, dan warnawarna yang sesuai dengan hiasan upacara ritual. Bangunan adat adalah lambang kepribadian serta prilaku masyarakatyang memiliki bangunan tersebut, bangunan adat yang melambangkan kepribadian suatu suku atau marga di suatu daerah.

Dalam kajian estetika timur Bentuk bangunan sopo godang di huta godang bentuk tiang sebagai penyangga bangunan umumnya sebuah kayu balok bulat. Sebagai penyangga bangunan rumah adat, memiliki makna simbol adat, demikian pula halnya bagi tiang bangunan sopo godang. Tiang banguna sopo godang huta godang memiliki 10 buah tiang bangunan, 5 buah berada di samping kiri dan 5 buah berada disamping kanan. Sopo godang memiliki tangga ganjil yaitu 3 buah, letak dan tangga ini tergantung dengan kebutuhan. Letak tangga yang terdapat di rumah adat sopo godang Mandailing memiliki arti yang sangat penting, letak tangga dan jumlah anak tangga mentukan status atau kedudukan dalam prilaku adat. Tangga yang memiliki bangunan rumah dengan genap biasanya merupakan dari penguasa raja.

Komposisi Sopo Godang mengarah ke Bagas godang. Karena itu, kedua bangunan tersebut dimuliakan dalam kehidupan masyarakat. Adat istiadat Mandailing menjadikan kedua bangunan adat tersebut sebagai milik masyarakat Huta tanpa mengurangi kemulian Raja dan keluarganya yang berhak penuh menempati Bagas Godang. Oleh kerana itu, pada masa lampau Bagas Godang dan Sopo Godang maupun Alaman Bolak Silangse Utang dengan sengaja tidak berpagar atau bertembok memisahkannya dari rumahrumah penduduk Huta. Sopo Godang harus mempunyai sebidang halaman yang cukup luas. Oleh 
kerana itulah maka kedua bangunan tersebut ditempatkan pada satu lokasi yang cukup luas dan datar dalam Huta. Halaman Bagas Godang dinamakan Alaman Bolak Silangse Utang (Halaman Luas Pelunas Hutang). Sesiapa yang mencari perlindungan dari ancaman yang membahayakan dirinya boleh mendapat keselamatan dalam halaman ini. Menurut adat Mandailing, pada saat orang yang sedang dalam bahaya memasuki halaman ini, ia dilindungi Raja, dan tidak boleh diganggu-gugat.

Dalam kajian ini terdapat juga warna khas dalam adat sopo godang Mandailing, warna ini tidak lepas dari adat. Dalam bindu segi tiga atau tutup ari selalu menonjolkan warna khas yaitu merah, hitam dan putih. Ornamen-ornamen itu sebagian besar diberi warna na rara (merah), na lomlom (hitam) dan na bontar (putih) yang erat kaitannya dengan kosmologi Mandailing. Dalam hal ini, na rara melambangkan kekuatan, keberanian dan kepahlawanan; na bontar melambangkan kesucian, kejujuran dan kebaikan; na lomlom melambangkan kegaiban (alam gaib) dalam sistem kepercayaan animisme yang disebut Sipelebegu. Warna pasti tidak datang dengan sendirinya melainkan akan tetap dimusyawarahkan oleh masyaraka daerah, dan akan disepakati dalam rumah adat sopo godang disetujui oleh raja. Dalam dunia timur, aspek, rasa, luar akal, misteri, teka teki, kekacauan fantasi diterima sebagai suatu dunia yang berada diatas yang bersifat rasional. Masyarakat timur adalah masyarakat yang hidup dalam kebudayaan yang senantiasa dengan menggukan bahasa alam. Begitu juga dengan masyarakat mandailing dalam menentukan warna-warna alam pada rumah adat sopo godang mandailing, karna bagi mereka alam merupakan bahasa tubuh bagi masyarakat daerah.

\section{KESIMPULA DAN SARAN}

\section{Kesimpulan}

Rumah adat Mandailing mencerminkan keagungan Huta sebagai sebuah masyarakat yang mampu berdiri sendiri, salah stunya yaitu dengan membentuk dan menjalankan pemerintahannya sendiri dan serta mempertahankan budayanya sendiri. Sopo Godang adalah rumah adat Mandailing Natal, Sopo Godang merupakan balai adat, dan tempat berkesenian bagi masyarakat Mandailing Natal. Sopo godang ini terletak persis didepan rumah Bagas Godang, dengan ukuran lebih kecil di bandingkan dengan Bagas Godang, dan arahnya menghadap ke bagas godang. Sopo Godang ini sudah lama berdiri dimana waktu itu di bawah pimpinan raja junjungan. Sampai sekaran Sopo Godang Ini masih utuh dan letaknya di huta godang ulu pungkut. Sopo Godang ini sangatlah berarti buat masyarakat mandailing, karena di dalam Sopo Godang ini sangat tegak hukum dan adat.

Sopo Godang menegakkan keadilan seadil-adilnya, jika ada seseorang yang bersalah akan di adili di dalam sopo godang ini baik itu anak raja maupun masyarakat dan disaksikan oleh masyarakat itu sendiri, supaya masyarakat tau akan perkara yang akan di adili oleh raja. dan di dalamnya terdapat juga alat berkesenian seperti gordang sembilan. Gordang sembilan ini gunanya untuk memaiinkan alat musik dengan sembilan irama, diantaranya untuk memanggil si baso ( makhluk gaib ) untuk mendatangkan hujan.

Tiangnya yang kokoh dan kuat yang terdapat ganjil, anak tangga yang ganjil. Itu semua mereka buat dengan angka ganjil, begitu juga dengan alat kesenian yang ganjil. Karna bagi mereka angka ganjil merupakan angka yang paling tinggi. bangunan adat tersebut melambangkan keagungan masyarakat Huta sebagai suatu masyarakat yang diakui sah kemandiriannya dalam menjalankan pemerintahan dan adat dalam masyarakat Mandailing.

\section{Saran}

Saran yang dapat disampaikan peneliti dapat digunakan sebagai bahan pedoman untuk masyarakat dan mahasiswa dll. Untuk dapat lebih melestarikan budaya-budaya lokal yang hampir tenggelam dengan keadaan modren yang sekarang. Diharapkan untuk tidak hanya para mahasiswa dan dosen saja yang dapat mengetahui budaya-budaya kita, tetapi juga para masyarakat itu sendiri. Berharap kedepan penelitian budaya ini akan tambah lebih baik lagi untuk menggali tentang budaya lokal lainnya.

\section{DAFTAR RUJUKAN}

Kartika, Dharsono Sony. (2007). Estetika. Bandung: Rekaya Sains

Kholilah, Anni. (2014). Bentuk Dan Fungsi Rumah Adat Raja Pamusuk Mandailing.

Padangpanjang: Program Pascasarjana Institut Seni Indonesia Padangpanjang.

Kholilah, Anni. (2018). Bentuk Dan Fungsi Sopo Godang Tapanuli Selatan Mandailing Natal. Cilacap: Institut Agama Islam Imam Ghozali.

Lubis, Syahmerdan. (1997). Adat Hangoluan

Mandailing, Tapanuli Selatan. Medan: S

Lubis.

Nasution, Pandapotan. (2005). Adat Budaya

Mandailing dalam Tantangan Zaman. Sumatera Utara: FORKALA. 
Sachari, Agus. (2002). Estetika Makna Simbol dan Daya. Bandung: ITB.

Situmorang, Oloan. (1979). Arti Perlambangan Dalam Seni Ornamen Pada Rumah Adat Mandailing. Medan: CV Angkasa Wira Usaha.

Situmorang, Oloan. (1979). Mengenali Bangunan

Serta Ornamen Rumah Adat Daerah

Mandailing Dan Hubungannya Dengan

Perlambangan Adat. Medan: CV Angkasa

Wira Usaha. 